\title{
Curcumin reduces the expression of survivin, leading to enhancement of arsenic trioxide-induced apoptosis in myelodysplastic syndrome and leukemia stem-like cells
}

\author{
YINGJIAN ZENG $^{1 *}$, GUANGYANG WENG ${ }^{2 *}$, JIAXIN FAN $^{1}$, ZHANGQIU LI $^{1}$, JIANWEI WU ${ }^{1}$, \\ YUANMING $\mathrm{LI}^{1}$, RONG ZHENG ${ }^{1}$, PINGFANG XIA ${ }^{1}$ and KUNYUAN GUO ${ }^{3}$
}

\begin{abstract}
${ }^{1}$ Department of Hematology, Affiliated Jiangmen Traditional Chinese Medical Hospital of Jinan University, Jiangmen, Guangdong 529000; ${ }^{2}$ Deparment of Hematology, Shenzhen Second People's Hospital, The First Affiliated Hospital of Shenzhen University, Shenzhen 518000; ${ }^{3}$ Department of Hematology, Zhujiang Hospital, Southern Medical University, Guangzhou 510282, P.R. China
\end{abstract}

Received February 17, 2016; Accepted April 19, 2016

DOI: $10.3892 /$ or.2016.4944

\begin{abstract}
Low response, treatment-related complications and relapse due to the low sensitivity of myelodysplastic syndrome (MDS) and leukemia stem cells (LSCs) or pre-LSCs to arsenic trioxide (ATO), represent the main problems following treatment with ATO alone in patients with MDS. To solve these problems, a chemosensitization agent can be applied to increase the susceptibility of these cells to ATO. Curcumin (CUR), which possesses a wide range of anticancer activities, is a commonly used chemosensitization agent for various types of tumors, including hematopoietic malignancies. In the present study, we investigated the cytotoxic effects and potential mechanisms in MDS-SKM-1 and leukemia stem-like KG1a cells treated with CUR and ATO alone or in combination. CUR and ATO exhibited growth inhibition detected by MTT assays and apoptosis analyzed by Annexin V/PI analyses in both SKM-1 and KG1a cells. Apoptosis of SKM-1 and KG1a cells determined by Annexin V/PI was significantly enhanced in the combination groups compared with the groups treated with either agent alone. Further evaluation was performed by western blotting for two hallmark markers of apoptosis, caspase-3 and cleaved-PARP. Co-treatment of the cells with CUR and ATO resulted in significant synergistic effects. In SKM-1 and KG1a cells, 31 and 13 proteins analyzed by protein array assays were modulated, respectively. Notably, survivin protein expression levels were downregulated in both cell
\end{abstract}

Correspondence to: Dr Yingjian Zeng, Department of Hematology, Affiliated Jiangmen Traditional Chinese Medical Hospital of Jinan University, 30 Huayuan East Road, Jiangmen, Guangdong 529000, P.R. China

E-mail: 13431762390@163.com

${ }^{*}$ Contributed equally

Key words: curcumin, arsenic trioxide, myelodysplastic syndrome, leukemia stem cells, apoptosis, synergism effect, survivin lines treated with CUR alone and in combination with ATO, particularly in the latter case. Susceptibility to apoptosis was significantly increased in SKM-1 and KG1a cells treated with siRNA-survivin and ATO. These results suggested that CUR increased the sensitivity of SKM-1 and KG1a cells to ATO by downregulating the expression of survivin.

\section{Introduction}

Myelodysplastic syndrome (MDS) is a heterogeneous group of clonal hematopoietic stem cell malignancies characterized by bone marrow failure, morphologic dysplasia of bone marrow cells, pancytopenia in the peripheral blood and a high risk of acute myeloid leukemia (1,2). MDS tends to occur in the elderly (median age at diagnosis, $71-76$ years) $(3,4)$ who cannot afford the complications following hematopoietic stem cell transplantation (HSCT) and high intensity chemotherapy (5). Low doses of arsenic trioxide (ATO), a common agent used for the treatment of patients with acute promyelocytic leukemia (APL), can induce complete remission without myelosuppression and causes only few adverse effects $(6,7)$. Consequently, it has similarly been applied to treat MDS patients alone or in combination with another agent in clinical trials (8-10). Unfortunately, the hematological improvement rates of MDS patients were only $20-30 \%$ (11). Additionally, high doses of ATO cause intolerable toxicity (12). Furthermore, MDS, as a pre-leukemia status, exhibits the characteristics of leukemia transformation and relapse, which may be closely associated with pre-leukemic stem cells (pre-LSCs) and leukemic stem cells (LSCs) $(13,14)$. Effective killing of MDS cells, as well as pre-LSCs and LSCs, by combining ATO with a chemosensitizer may be a potential strategy to improve the response rate of MDS patients to ATO treatment, block leukemic transformation and prevent MDS relapse. Previous studies have reported the combination of ATO with another agent, including thalidomide, ascorbic acid and cytarabine, in vitro and in vivo $(11,15,16)$; however, few studies have been conducted to assess the combination of ATO with a chemosensitizer, particularly curcumin (CUR). 
CUR, a type of polyphenol plant derived from the rhizome of turmeric, is widely used as chemopreventive and chemosensitization agent and has extensively been studied in various types of cancers, including leukemia, colon, breast, liver and lung cancer (17). Accumulating research has revealed that CUR sensitizes neoplasms to diverse chemotherapeutic drugs in vivo and in vitro, including vincristine, melphalan, butyrate, cisplatin, 5-FU, vinorelbine, gemcitabine and oxaliplatin (18-22). CUR interferes with diverse processes in cancer cells, including the cell cycle, apoptosis, proliferation, survival, invasion, metastasis and inflammation (23), which may be associated with its sensitizing effect. It downregulated various growth regulatory pathways and targets including $N F-\kappa B$, STAT3, COX2, Akt, apoptosis-related proteins, growth factor receptors and multidrug-resistance proteins (17). More importantly, CUR is readily available and safe, thus representing an ideal chemosensitizer.

The SKM-1 cell line, which was established from leukemia cells from a 76-year-old Japanese male patient with overt monoblastic leukemia following MDS (24-26), is an established MDS cell model for investigating MDS in vitro. KG1a cells demonstrate characteristics of LSCs, including self-renewal potential, resistance to chemotherapy and immunotherapy, and a CD $34^{+} \mathrm{CD} 38^{-}$cell phenotype $(27,28)$. KG1a cells are thus considered to be leukemia stem-like cells, and they provide an ideal cell model for investigating LSCs in vitro.

In the present study, we explored the ability of CUR to sensitize SKM-1 and KGla cells to ATO by investigating the cytotoxic efficiency and molecular mechanisms of CUR and ATO alone and in combination in SKM-1 and KGla cells in vitro.

\section{Materials and methods}

Reagents. RPMI-1640 medium (11875093), fetal bovine serum (FBS) (16000-044) (both from Gibco, Grand Island, NY, USA) penicillin and streptomycin (P11-010; PAA Laboratories, Dartmouth, MA, USA), dimethyl sulfoxide (DMSO) (A3009; AppliChem GmbH, Darmstadt, Germany), CUR (458-37-7; Sigma, St. Louis, MO, USA), ATO (ShuangLu Corp., Beijing, China), 3-(4,5-dimethylthiazol-2-yl)-2,5-diphenyltetrazolium bromide (MTT; Seebio Biotech, Inc., Shanghai, China), hydroxypropyl methylcellulose (MP Biomedicals, Santa Ana, CA, USA), the FITC Annexin V apoptosis detection kit I, anti-PARP (1:500) (both from BD Biosciences, San Jose, CA, USA) anti-caspase-3 $(1: 5,000)$ [Cell Signaling Technology (CST) Danvers, MA, USA] anti-survivin (1:5,000; BD Biosciences), the Human Apoptosis Antibody Array kit (RayBio, Norcross, GA, USA), electrophoresis apparatus trophoresis (EPS200; Tanon Science and Technology Co., Ltd., Shanghai, China), and the LI-COR Odyssey scanner (LI-COR, Lincoln, NE, USA) were used.

Cell lines and culture. SKM-1 cells were purchased from Jennio Biotech Co. (Guangzhou, China), and KGla cells were provided by She et al (28). Cells were cultured in RPMI-1640 medium with $10 \%$ inactivated FBS, penicillin and streptomycin at $37^{\circ} \mathrm{C}$ with $5 \% \mathrm{CO}_{2}$.

Cell viability assays. Cell viability was detected using the MTT assay. SKM-1 and KG1a cells in logarithmic phase were seeded into 96 -well plates at $5 \times 10^{5}$ cells $/ \mathrm{ml}$ in the presence or absence of the indicated test samples in a final volume of $0.2 \mathrm{ml}$ for 24 or $48 \mathrm{~h}$ at $37^{\circ} \mathrm{C}$ with $5 \% \mathrm{CO}_{2}$. Next, $20 \mu \mathrm{l}$ of MTT solution [5 $\mathrm{mg} / \mathrm{ml}$ in phosphate-buffered saline (PBS)] was added to each well and incubated for $4 \mathrm{~h}$ at $37^{\circ} \mathrm{C}$, followed by the addition of $200 \mu \mathrm{l}$ of DMSO. Finally, the plates were gently shaken and analyzed at $490 \mathrm{~nm}$ using a microplate reader (Multiskan MK3; Shanghai). Each experiment was performed in triplicate. The cell viabilities in the two cell lines were calculated as follows: Inhibition $(\%)=1$ - (OD value of experimental samples/OD value of control samples) x $100 \%$.

Methylcellulose colony formation test. Approximately 500 untreated or treated cells/well were cultured in RPMI-1640 medium supplemented with $0.9 \%$ methylcellulose and $20 \%$ FBS in a final volume of $2 \mathrm{ml}$ of 24 -well plate at $37^{\circ} \mathrm{C}$ with $5 \%$ $\mathrm{CO}_{2}$. The number of colonies formed ( $>50$ cells) was counted under a light microscope after 14 days of incubation. The experiments were performed in triplicate.

Analysis of apoptosis using Annexin V/PI. The apoptotic cells were examined by Annexin $\mathrm{V}$ binding assays according to the manufacturer's instructions (WinMDI 2.9 software; BD Corporation). Briefly, $\sim 1.0 \times 10^{6}$ cells in 6 -well plates were treated with various concentrations of the indicated test samples at $37^{\circ} \mathrm{C}$ with $5 \% \mathrm{CO}_{2}$ for $48 \mathrm{~h}$. The cells were then harvested for subsequent experiments. The cells were washed three times with cold PBS and then re-suspended in $1 \mathrm{X}$ binding buffer at a concentration of $1 \times 10^{6}$ cells $/ \mathrm{ml}$, and $100 \mu 1$ of the solution $\left(1 \times 10^{5}\right.$ cells) was transferred to a 5-ml culture tube, followed by the addition of $5 \mu \mathrm{l}$ of FITC Annexin V and $5 \mu \mathrm{PI}$ and incubation for $15 \mathrm{~min}$ at room temperature $\left(25^{\circ} \mathrm{C}\right)$ in the dark. Finally, $400 \mu \mathrm{l}$ of $1 \mathrm{X}$ binding buffer was added to each tube, and the cells were analyzed by flow cytometry.

Western blot analysis. Total cellular proteins of SKM-1 and KG1a cells were isolated using lysis buffer (RIPA). Equal amounts of protein were subjected to 10 or $15 \%$ polyacrylamide gel electrophoresis and transferred to polyvinylidene difluoride (PVDF) membranes. The membranes were blocked with $5 \%$ skim-milk and incubated with primary antibodies (anti-PARP, anti-caspase-3 and anti-survivin) overnight at $4^{\circ} \mathrm{C}$, followed by horseradish peroxidase-conjugated anti-mouse secondary antibody at room temperature $\left(25^{\circ} \mathrm{C}\right)$ for $2 \mathrm{~h}$. The protein bands were imaged using chemiluminescence reagent (CTB; USA), and the band density values were analyzed using ImageJ software. Glyceraldehyde-3-phosphate dehydrogenase (GAPDH; HC301; 1:5,000) served as the internal reference.

Short interfering RNA (siRNA) transfection of survivin. SKM-1 and KG1a cells in logarithmic phase were moderately $\left(10^{6} / \mathrm{ml}\right)$ inoculated into 6 -well plates for $24 \mathrm{~h}$ before transfection. Control scrambled siRNA was synthesized and purchased from GenePharma, Co., Ltd. (Shanghai, China). siRNA survivin (10 $\mu \mathrm{M})$ : 5'-GAGCCAAGAACAAAATTGC-3' (29) or control scramble sequences were transfected using Lipofectamine 2000 reagent (Invitrogen) strictly according to the manufacturer's protocol. Briefly, $5 \mu$ l of Lipofectamine 2000 was diluted in $250 \mu \mathrm{l}$ of Opti-MEM medium (Invitrogen) in each well. The mixture was gently added to a solution 
A

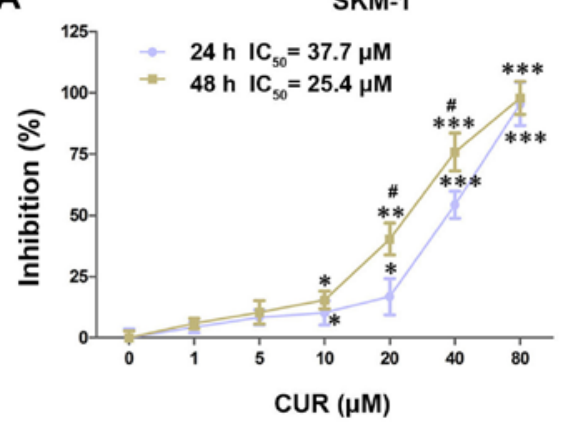

KG1a

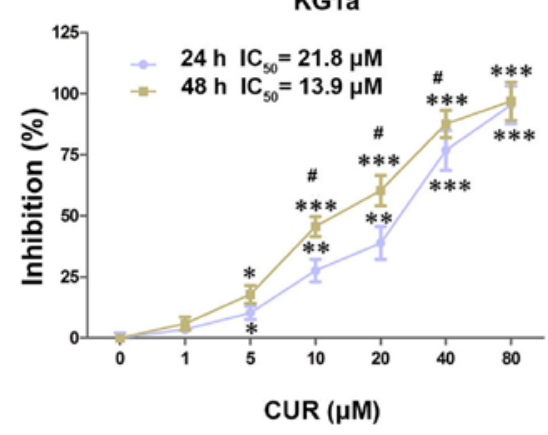

$\operatorname{CUR}(\mu \mathrm{M})$

\section{B}
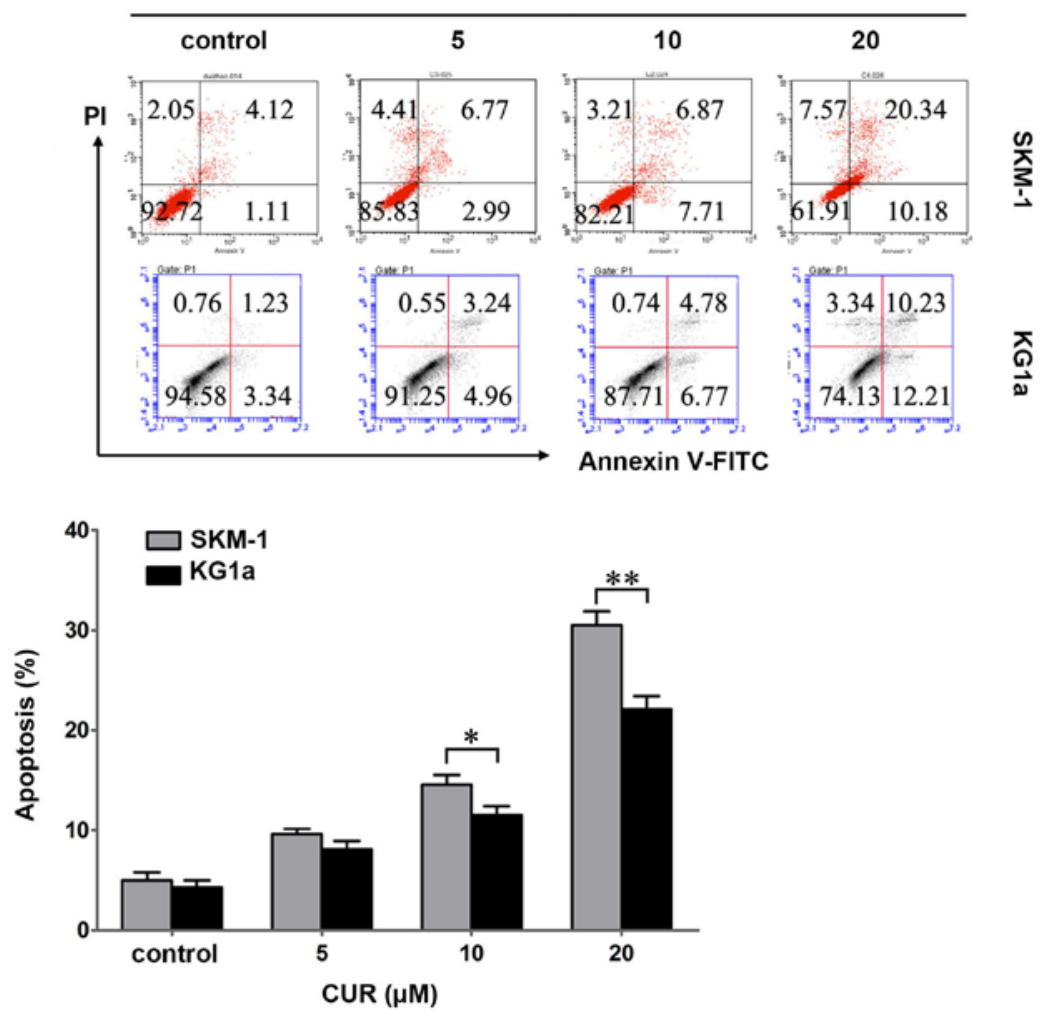

Figure 1. CUR inhibits cell growth and induces cell apoptosis in SKM-1 and KG1a cells. (A) SKM-1 and KG1a cells were exposed to different concentrations

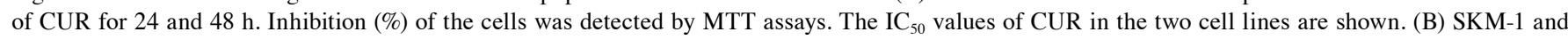
KG1a cells were treated with various concentrations of CUR for $48 \mathrm{~h}$, and then apoptotic cells were analyzed by staining using Annexin V/PI. The MTT and apoptosis results revealed dose-dependent effects in the two cell lines. The graph displays the means \pm SD of three independent experiments conducted in triplicate; ${ }^{*} \mathrm{p}<0.05,{ }^{* *} \mathrm{p}<0.01,{ }^{* * *} \mathrm{p}<0.001$ (compared with the control); ${ }^{*} \mathrm{p}<0.05$ (24 vs. $48 \mathrm{~h}$ ).

containing siRNA in $250 \mu 1$ of Opti-MEM medium, incubated for $20 \mathrm{~min}$, and then added to the plates. After transfection with siRNA for $24 \mathrm{~h}$, the cells were harvested for subsequent assays.

Analysis of apoptosis-related proteins by RayBio arrays. The expressions of 43 apoptosis-related proteins were analyzed using a Human Apoptosis Antibody Array kit (RayBio, Norcross, GA, USA). Briefly, according to instructions (available from the RayBiotech Corp. official website (http://www.raybiotech.com/), each of the capture antibodies was printed on the membranes, followed by the addition of the treated or untreated cell lysate. After extensive washing, the membranes were incubated with a cocktail of biotin-conjugated anti-apoptotic protein antibodies. After incubation with the infrared fluorescent agent-streptavidin, the fluorescence signals were visualized using a LI-COR Odyssey scanner.

Statistical analysis. Data are represented as the mean \pm standard deviation (SD) and analyzed using SPSS 13.0 and GraphPad Prism 5 software. Means of different groups were compared using one-way ANOVA followed by Bonferroni's multiple comparisons to evaluate the differences between two groups under multiple conditions. When the data failed the normality test, the Kruskal-Wallis one-way ANOVA on ranks was used for data that failed the normality test. A value of $\mathrm{p}<0.05$ was considered statistically significant. CompuSyn software was used to evaluate the synergistic effects of drug combinations. The combination index (CI) was generated by 
A

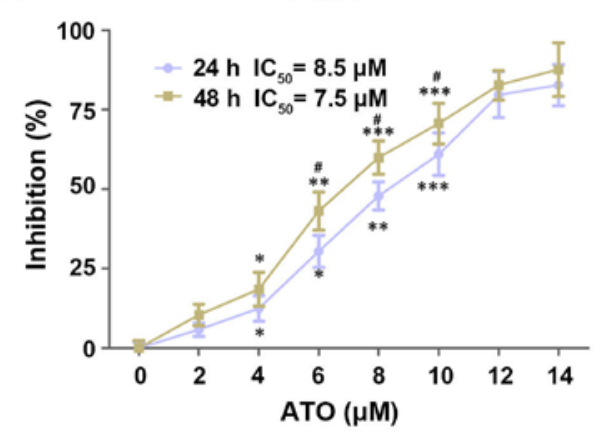

KG1a

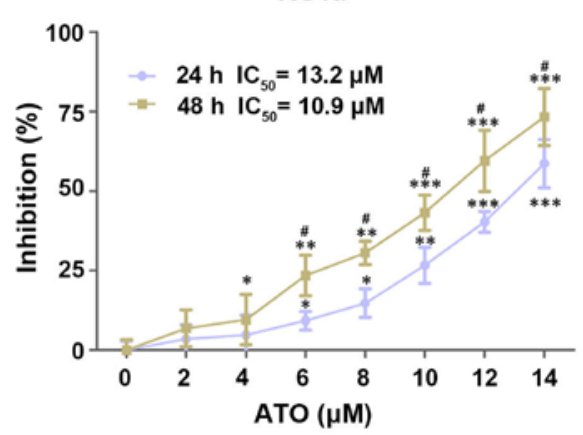

B
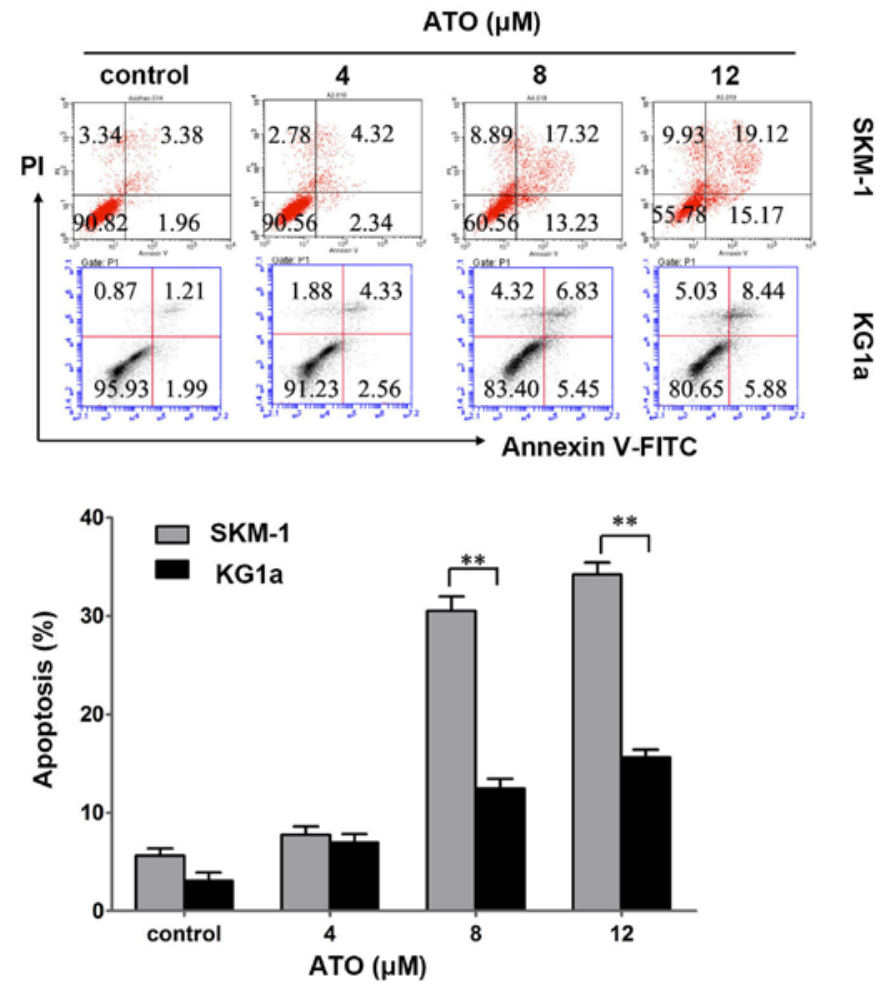

Figure 2. ATO inhibits cell growth and induces cell apoptosis in SKM-1 and KGla cells. (A) SKM-1 and KGla cells were exposed to different concentrations of ATO for 24 and $48 \mathrm{~h}$. The inhibitory rates of the cells were detected by MTT assays. The $\mathrm{IC}_{50}$ value of ATO in the two cell lines are shown. (B) SKM-1 and KGla cells were treated with different concentrations of ATO for $48 \mathrm{~h}$, and then apoptotic cells were analyzed by staining with Annexin V/PI. The MTT and apoptosis results showed a dose-dependent effect in the two cell lines. The data are expressed as the means $\pm \mathrm{SD}$ of three independent experiments; " $\mathrm{p}<0.05$, ${ }^{* * *} \mathrm{p}<0.01,{ }^{* * *} \mathrm{p}<0.001$ (compared with the control); ${ }^{\#} \mathrm{p}<0.05$ (24 vs. $48 \mathrm{~h}$ ).

CompuSyn software, where $\mathrm{CI}<1, \mathrm{CI}=1$ and $\mathrm{CI}>1$ indicated synergism, additive effect and antagonism, respectively.

\section{Results}

CUR inhibits cell growth and induces cell apoptosis in SKM-1 and KGla cells. SKM-1 and KG1a cells were treated with various concentrations of CUR $(0-80 \mu \mathrm{M})$ for 24 and $48 \mathrm{~h}$, and the cytotoxic effects were detected by MTT assays. CUR exhibited a growth inhibitory effect dose- and time-dependently in the two cell lines (Fig. 1A). The $\mathrm{IC}_{50}$ values in SKM-1 cells at 24 and $48 \mathrm{~h}$ were 37.7 and $25.4 \mu \mathrm{M}$, respectively, and those in KGla cells were 21.8 and $13.9 \mu \mathrm{M}$, respectively.

To explore whether CUR induced apoptosis in SKM-1 and KG1a cells, the two cell lines were exposed to CUR for $48 \mathrm{~h}$ followed by detection by Annexin V/PI. CUR induced early and late apoptosis in a dose-dependent manner in the two cell lines (Fig. 1B). By contrast, CUR induced significantly more apoptosis in SKM-1 cells than in the KG1a cells at an equivalent concentration (Fig. 1B), indicating that SKM-1 cells were more sensitive to CUR when compared with KGla cells in terms of apoptosis-induction. These results were contrary to cytotoxic effects that the growth inhibitory effect of CUR is higher for KGla cells than in the SKM-1 cells. This finding demonstrated apoptosis may not be the predominant mode of cell death, and it may also occur through alternate pathways.

ATO inhibits cell growth and induces cell apoptosis in SKM-1 and KGla cells. To evaluate the cytotoxic effects of ATO on the two cell lines, SKM-1 and KG1a cells were treated with various concentrations of ATO $(0-14 \mu \mathrm{M})$ for 24 and $48 \mathrm{~h}$, and the cytotoxic effects were detected by MTT assays. ATO exhibited growth inhibitory effects dose- and time-dependently in the two cell lines (Fig. 2A). The $\mathrm{IC}_{50}$ values in SKM-1 
A Concentration $(\mu \mathrm{M})$
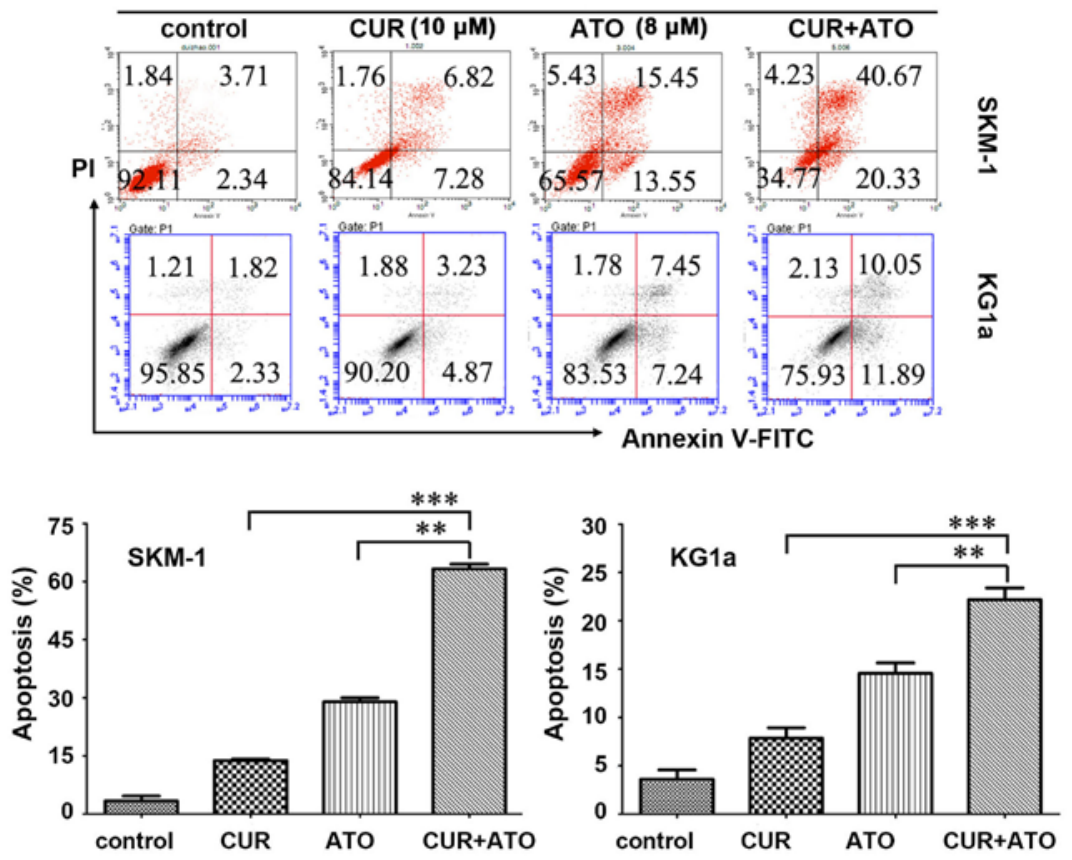

B

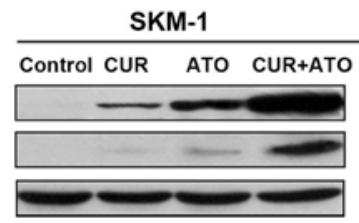

KG1a

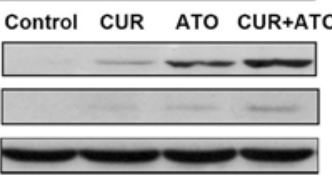

Cleaved PARP

Cleaved caspase-3

SKM-1

KG1a
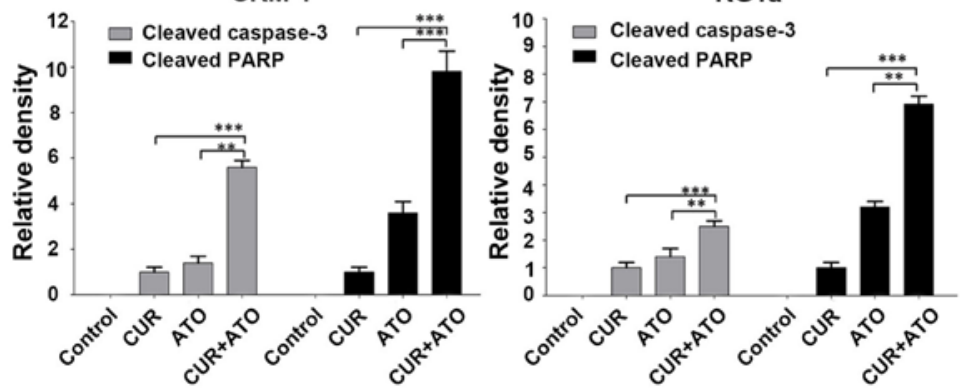

Figure 3. CUR increases ATO-induced apoptosis by upregulating cleaved caspase-3 followed by PARP degradation in SKM-1 and KG1a cells. SKM-1 and KGla cells were exposed to concentrations of CUR $(10 \mu \mathrm{M})$ or ATO $(8 \mu \mathrm{M})$ alone or CUR + ATO for $48 \mathrm{~h}$ and analyzed by (A) flow cytometry and (B) western blot analysis. Western blot analysis revealed cleaved caspase-3 and cleaved PARP fragment. (B) Representative data are shown. Data shown were from three independent experiments conducted in triplicate. The results are expressed as the means $\pm \mathrm{SD} ;{ }^{* *} \mathrm{p}<0.01,{ }^{* * *} \mathrm{p}<0.001$. The control groups were blank groups without treatment with CUR and ATO alone or in combination.

cells at 24 and $48 \mathrm{~h}$ were 8.5 and $7.5 \mu \mathrm{M}$, respectively, and those in KG1a cells were 13.2 and $10.9 \mu \mathrm{M}$, respectively.

To clarity whether ATO induced apoptosis in SKM-1 and KGla cells, the two cell lines were exposed to ATO for $48 \mathrm{~h}$ followed by detection with Annexin V/PI. ATO induced early and late apoptosis in a dose-dependent manner in the two cell lines (Fig. 2B). Similar to the results obtained for CUR, ATO induced significantly more apoptosis in SKM-1 cells than in KGla cells at an equivalent concentration (Fig. 2B), indicating SKM-1 cells were more sensitive to ATO compared with KGla cells.

CUR increases ATO-induced apoptosis by upregulating cleaved caspase-3 followed by PARP degradation in
SKM-1 and KGla cells. We determined whether CUR could increase ATO-induced apoptosis in SKM-1 and KG1a cells by evaluating the pro-apoptotic effects of CUR $(10 \mu \mathrm{M})$ and ATO $(8 \mu \mathrm{M})$ alone and in combination (CUR + ATO) using Annexin V/PI. Apoptosis of the two cell lines increased significantly in the CUR + ATO group compared with the CUR or ATO alone groups (Fig. 3A), particularly in SKM-1 cells. For example, apoptotic SKM-1 cells in response to CUR and ATO alone and in combination were $13.7 \pm 0.4,28.9 \pm 0.9$ and $63.2 \pm 1.3 \%$, respectively. Western blot analysis further revealed that co-treatment with CUR and ATO significantly induced caspase- 3 activation and PARP cleavage (Fig. 3B), two hallmarks of apoptosis, in both SKM-1 and KGla cells, which was consistent with the results obtained by Annexin V/PI. 
A
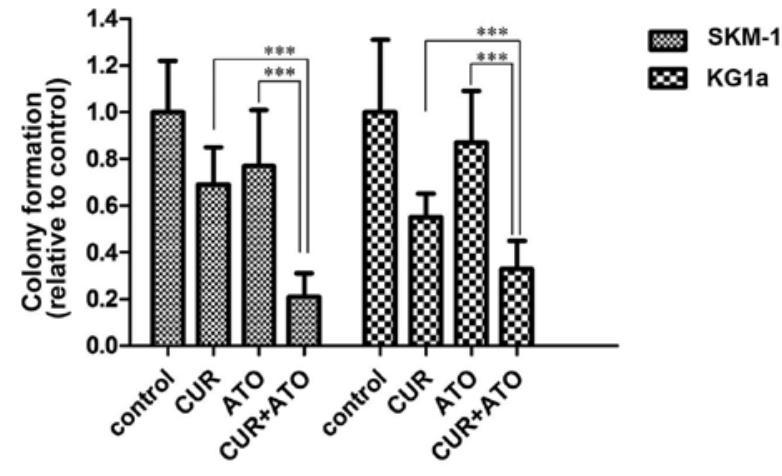

B
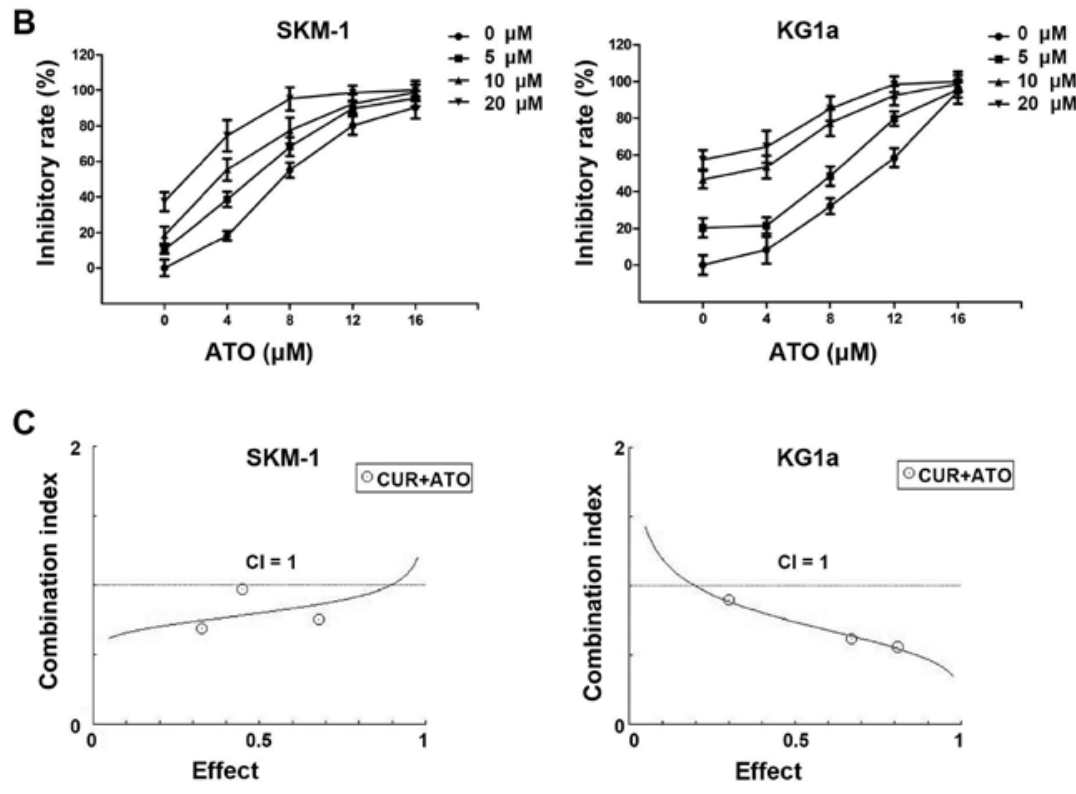

Figure 4. CUR synergistically enhances the cytotoxic effects of ATO in SKM-1 and KGla cells. (A) SKM-1 and KGla cells were treated with CUR (10 $\mu$ M) and ATO $(8 \mu \mathrm{M})$ alone or in combination for $48 \mathrm{~h}$ followed by inoculation in a methylcellulose cloning system for 14 days and observation and counting under a light microscope (magnification, $\mathrm{x} 40$ ). More than 50 cells were considered to indicate colony formation; ${ }^{* * *} \mathrm{p}<0.001$, compared with the combination groups (CUR + ATO). Results are expressed as the means \pm SD of three independent experiments. (B) Dose-response curves for ATO at various CUR concentrations. Cells were treated with 0-16 $\mu \mathrm{M}$ ATO and 0-20 $\mu \mathrm{M}$ CUR for $48 \mathrm{~h}$, and then MTT assays were performed. The mean viability relative to the control was plotted against the ATO concentration. The error bars represent the $95 \%$ confidence intervals of three independent experiments. (C) Chou-Talalay synergy analysis of the interaction between CUR and ATO based on the cell viability data. The results are representative of three independent experiments. A combination index (CI) value $<1$ indicates synergism between CUR and ATO.

These results strongly indicated that CUR was able to enhance ATO-induced apoptosis and sensitize SKM-1 and KG1a cells to ATO.

CUR synergistically enhances the cytotoxic effects of ATO in SKM-1 and KGla cells. To evaluate the ability of CUR to enhance the cytotoxic effects of ATO, we assessed the inhibition of the clonogenicity of CUR and ATO alone or in combination in SKM-1 and KG1a cells. Cells were treated with CUR $(10 \mu \mathrm{M})$ and ATO $(8 \mu \mathrm{M})$ alone or in combination for $48 \mathrm{~h}$, followed by inoculation in a methylcellulose for 14 days, and observation and counting under a light microscope. Colony formation was significantly reduced in the combination groups compared with the CUR or ATO alone groups (Fig. 4A), which indicated that CUR enhanced the ATO-induced inhibition of colony formation.

Furthermore, we detected the inhibition of survival in response to CUR and ATO alone or in combination in SKM-1 and KG1a cells. Cells were exposed to a range of concentrations of ATO $(0-16 \mu \mathrm{M})$ and CUR $(0-20 \mu \mathrm{M})$ for $48 \mathrm{~h}$. The cell viability in each sample was measured using MTT assays. The dose-response curve of ATO was shifted to the left by CUR (Fig. 4B). Accordingly, CUR enhanced the cytotoxic effects of ATO on SKM-1 and KG1a cells. To evaluate the synergism of CUR and ATO in the two cell lines, cells were treated with combinations of the two drugs at different doses but at a constant ratio (CUR to ATO: 5-4, 10-8 and 20-16 $\mu \mathrm{M}$, respectively) for $48 \mathrm{~h}$. Synergistic effects were estimated using CompuSyn software. The CI values were $<1$ in both cell lines (Fig. 4C), demonstrating the synergism of CUR and ATO in combination.

In summary, these results demonstrated that CUR synergistically enhanced the cytotoxic effects of ATO and sensitized SKM-1 and KG1a cells to ATO.

Effects of CUR and ATO alone or in combination on the expression of apoptosis-related proteins in SKM-1 and KGla cells. To explore the mechanisms and potential targets by which CUR increased ATO-induced apoptosis, we detected 43 apoptosis-related proteins using apoptosis antibody array 
Table I. Expression of apoptosis-related proteins in the treated groups.

\begin{tabular}{|c|c|c|c|c|c|c|}
\hline \multirow[b]{2}{*}{$\begin{array}{l}\text { Apoptosis-related } \\
\text { proteins }\end{array}$} & \multicolumn{3}{|c|}{ SKM-1 } & \multicolumn{3}{|c|}{ KG1a } \\
\hline & $\begin{array}{l}\text { CUR/control } \\
\text { (fold-change) }\end{array}$ & $\begin{array}{l}\text { ATO/control } \\
\text { (fold-change) }\end{array}$ & $\begin{array}{c}\text { CUR+ATO/control } \\
\text { (fold-change) }\end{array}$ & $\begin{array}{l}\text { CUR/control } \\
\text { (fold-change) }\end{array}$ & $\begin{array}{l}\text { ATO/control } \\
\text { (fold-change) }\end{array}$ & $\begin{array}{c}\text { CUR+ATO/control } \\
\text { (fold-change) }\end{array}$ \\
\hline bad & 1.141 & 1.741 & $2.044^{\mathrm{a}}$ & 1.224 & 0.951 & 0.854 \\
\hline bax & 1.036 & 1.321 & 1.375 & 0.989 & 1.586 & $1.970^{\mathrm{a}}$ \\
\hline bcl-2 & 0.996 & 2.094 & $2.304^{\mathrm{a}}$ & 0.775 & 1.895 & $0.428^{\mathrm{b}}$ \\
\hline bcl-w & 1.083 & 1.892 & $2.098^{\mathrm{a}}$ & 0.852 & 1.907 & $0.667^{\mathrm{b}}$ \\
\hline BID & 0.739 & 0.272 & $0.543^{b}$ & 0.934 & 1.254 & 1.138 \\
\hline BIM & 1.146 & 2.071 & $2.389^{\mathrm{a}}$ & 0.883 & 0.962 & 0.843 \\
\hline caspase3 & 1.172 & 2.280 & $2.616^{\mathrm{a}}$ & 1.125 & 1.967 & $2.812^{\mathrm{a}}$ \\
\hline caspase8 & 1.118 & 2.952 & $3.118^{\mathrm{a}}$ & 1.157 & 1.075 & 1.152 \\
\hline CD40 & 0.930 & 1.534 & $1.634^{\mathrm{a}}$ & 0.789 & 0.870 & 0.771 \\
\hline CD40L & 1.081 & 1.803 & $1.879^{\mathrm{a}}$ & 0.805 & 0.867 & 0.816 \\
\hline cIAP-2 & 0.934 & 0.491 & $0.528^{b}$ & 0.664 & 1.320 & $0.345^{\mathrm{b}}$ \\
\hline cytoC & 1.011 & 2.156 & $2.918^{\mathrm{a}}$ & 1.314 & 1.916 & $2.848^{\mathrm{a}}$ \\
\hline DR6 & 1.063 & 1.448 & $1.588^{\mathrm{a}}$ & 0.792 & 0.924 & 0.822 \\
\hline Fas & 1.272 & 2.407 & $2.468^{\mathrm{a}}$ & 0.878 & 0.851 & 0.917 \\
\hline FasL & 1.080 & 1.601 & $1.694^{\mathrm{a}}$ & 0.841 & 1.026 & 0.858 \\
\hline HSP27 & 0.894 & 1.424 & 1.297 & 0.881 & 1.112 & 0.905 \\
\hline HSP60 & 1.084 & 1.604 & $1.721^{\mathrm{a}}$ & 0.858 & 0.972 & 0.899 \\
\hline HSP70 & 1.350 & 2.763 & $2.968^{\mathrm{a}}$ & 1.244 & 1.059 & 1.171 \\
\hline HTRA & 0.664 & 2.784 & $2.288^{\mathrm{a}}$ & 2.088 & 1.250 & $2.874^{\mathrm{a}}$ \\
\hline IGF-I & 0.891 & 1.187 & 1.163 & 0.794 & 1.068 & 0.720 \\
\hline IGF-II & 1.123 & 2.707 & $2.948^{\mathrm{a}}$ & 1.009 & 1.334 & 1.070 \\
\hline IGFBP-1 & 0.933 & 1.241 & 1.304 & 0.701 & 0.912 & $0.599^{b}$ \\
\hline IGFBP-2 & 0.971 & 1.223 & 1.253 & 0.794 & 0.978 & $0.479^{\mathrm{b}}$ \\
\hline IGFBP-3 & 1.119 & 1.769 & $1.888^{\mathrm{a}}$ & 0.749 & 0.891 & 0.878 \\
\hline IGFBP-4 & 0.974 & 1.980 & $2.012^{\mathrm{a}}$ & 0.782 & 0.961 & 0.805 \\
\hline IGFBP-5 & 1.002 & 4.794 & $4.849^{\mathrm{a}}$ & 0.810 & 0.952 & 0.860 \\
\hline IGFBP-6 & 1.102 & 0.811 & 0.905 & 0.829 & 1.042 & 0.867 \\
\hline IGF-1sR & 0.929 & 1.320 & 1.340 & 0.745 & 0.965 & 0.880 \\
\hline livin & 1.139 & 43.971 & $47.444^{\mathrm{a}}$ & 0.913 & 1.102 & 0.910 \\
\hline p21 & 1.044 & 1.664 & $2.177^{\mathrm{a}}$ & 0.921 & 0.980 & 0.960 \\
\hline p27 & 1.200 & 2.269 & $2.624^{\mathrm{a}}$ & 0.918 & 1.057 & 0.950 \\
\hline p53 & 1.097 & 2.970 & $3.364^{\mathrm{a}}$ & 0.946 & 1.081 & 1.005 \\
\hline SMAC & 1.025 & 0.979 & 1.069 & 1.032 & 1.062 & $1.523^{\mathrm{a}}$ \\
\hline Survivin & 0.805 & 2.118 & $0.360^{\mathrm{b}}$ & 0.607 & 1.805 & $0.215^{\mathrm{b}}$ \\
\hline sTNF-R1 & 1.051 & 1.492 & 1.323 & 0.836 & 1.152 & 0.772 \\
\hline sTNF-R2 & 0.819 & 1.124 & 1.042 & 0.693 & 0.909 & 0.733 \\
\hline TNF- $\alpha$ & 0.828 & 1.263 & 1.393 & 0.671 & 1.012 & 0.723 \\
\hline TNF- $\beta$ & 0.945 & 1.376 & $1.531^{\mathrm{a}}$ & 0.701 & 0.902 & 0.820 \\
\hline TRAILR-1 & 0.942 & 0.907 & 0.996 & 0.790 & 1.104 & 0.855 \\
\hline TRAILR-2 & 1.008 & 1.633 & $1.785^{\mathrm{a}}$ & 0.843 & 1.055 & 0.872 \\
\hline TRAILR-3 & 0.955 & 1.421 & $1.546^{\mathrm{a}}$ & 0.799 & 1.047 & 0.848 \\
\hline TRAILR-4 & 1.074 & 1.620 & $1.794^{\mathrm{a}}$ & 0.845 & 1.050 & 0.909 \\
\hline XIAP & 0.896 & 1.340 & $0.550^{\mathrm{b}}$ & 0.741 & 1.155 & $0.403^{\mathrm{b}}$ \\
\hline
\end{tabular}

SKM-1 and KG1a cells were treated with CUR $(10 \mu \mathrm{M})$ and ATO $(8 \mu \mathrm{M})$ alone or in combination for $48 \mathrm{~h}$, followed by detection using a protein array kit. Fold-changes $\leq 0.667$ or $\geq 1.5$ indicated proteins were modulated by these drugs. ${ }^{\mathrm{a} U p r e g u l a t e d,}$, ${ }^{\mathrm{b}} \mathrm{downregulated}$.

assays in SKM-1 and KG1a cells treated with CUR $(10 \mathrm{mM})$ and ATO $(8 \mathrm{mM})$ alone or in combination for $48 \mathrm{~h}$. Fold-changes $\leq 0.667$ or $\geq 1.5$ usually indicated that the protein expression level was modulated. As shown in Table I, 27 proteins were 
A

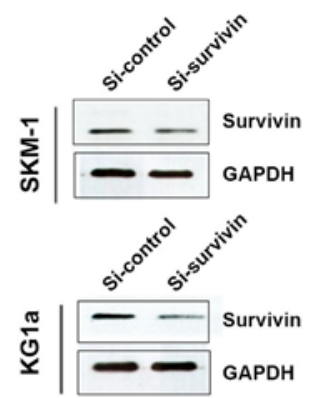

B

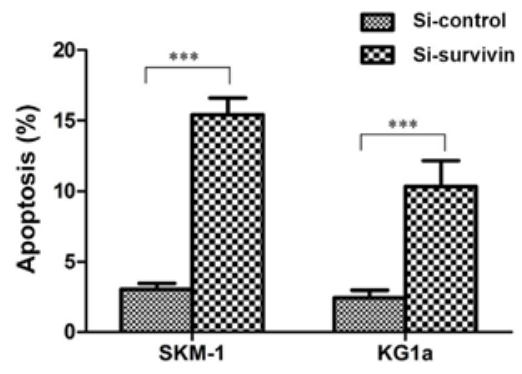

C
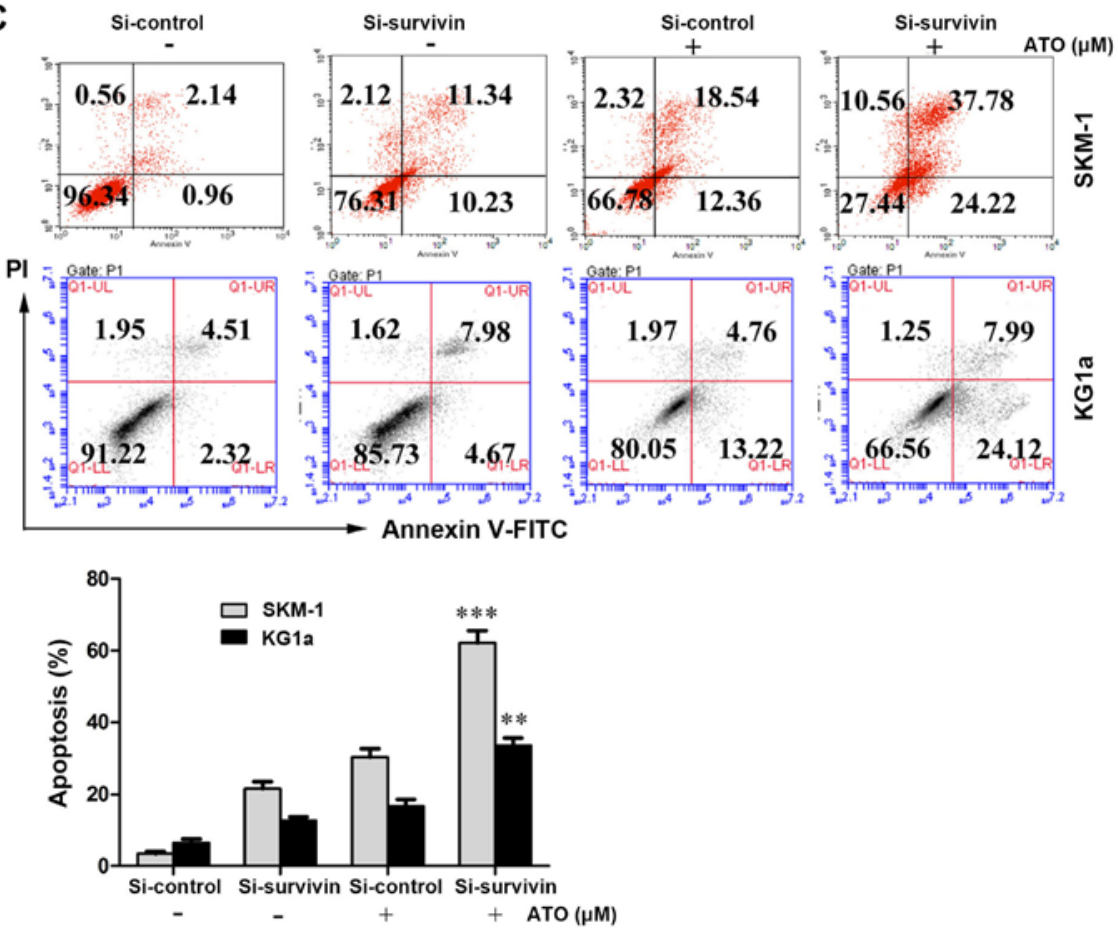

Figure 5. Suppression of survivin with siRNA induces apoptosis and increases susceptibility to ATO in SKM-1 and KG1a cells. SKM and KG1a cells were transfected with siRNA survivin or siRNA control for $24 \mathrm{~h}$. (A) The expression level of survivin were analyzed by western blotting. (B) Early and late apoptosis was detected by Annexin V/PI staining. Data are expressed as the means \pm SD of three independent experiments; ${ }^{* * *}$ p $<0.001$ (compared with the control). (C) SKM-1 and KGla cells were transfected with siRNA survivin or siRNA control for $24 \mathrm{~h}$, and then exposed to ATO ( $8 \mu \mathrm{M})$ for $48 \mathrm{~h}$ followed by detection by flow cytometry. The bar represents the means $\pm \mathrm{SD}$ of three independent experiments; ${ }^{* *} \mathrm{p}<0.05,{ }^{* * *} \mathrm{p}<0.001$ (compared with the control).

upregulated and four proteins were downregulated in SKM-1 cells in the drug combination group (Table I). In addition, five proteins were upregulated and seven proteins were downregulated in KGla cells in the drug combination group (Table I). Caspase-3 was upregulated significantly in both SKM-1 and KGla cells, in accordance with the results of the western blot analysis (Fig. 3B). The protein expression level of survivin was significantly upregulated in the ATO group, but significantly downregulated in the CUR and drug combination groups in both SKM-1 and KGla cells (Table I). Thus, we inferred that survivin may be a potential target of sensitizing SKM-1 and KGla cells to ATO.

Suppression of survivin with siRNA induces apoptosis and increases susceptibility to ATO in SKM-1 and KGla cells. We determined the role of CUR-induced downregulation of survivin in the sensitization of SKM-1 and KG1a cells to ATO by interfering with survivin expression using siRNA and evaluating the effect on apoptosis using Annexin V/PI assays. After treatment with siRNA-survivin for $24 \mathrm{~h}$, the protein expression level of survivin was significantly downregulated and apoptosis was significantly increased (similar to the CUR-treated groups) compared with the si-control groups in the two cell lines (Fig. 5A and B). As shown in Fig. 5C, the suppression of survivin by siRNA increased the susceptibility of SKM-1 and KG1a cells to ATO-induced apoptosis $(62.00 \%$ in SKM-1 cells and $32.11 \%$ in KG1a cells) compared with ATO alone $(30.90 \%$ in SKM-1 cells and $17.98 \%$ in KG1a cells). These results demonstrated that suppression of survivin expression could increase ATO-induced apoptosis in the two cell lines.

\section{Discussion}

MDS possesses the characteristics of a poor response to traditional chemotherapy (11), leukemic transformation (30), and easy relapse, which are associated with the age of the patient (tend to occur in the elderly) and LSCs or pre-LSCs (31). LSCs, which are characterized by self-renewal, chemoresistance and immune-resistance, are thus responsible for the origin, 
drug resistance and relapse of leukemia and leukemia-related disease $(28,32)$. Only by enhancing the sensitivity of MDS cells and LSCs or pre-LSCs to chemotherapeutic drugs can we effectively circumvent the above barriers. In the present study, we investigated the combination of CUR and ATO on MDS-SKM-1 cells and leukemia stem-like KGla cells to assess whether CUR could increase the susceptibility of these cells to ATO.

The anticancer activities of CUR have been extensively investigated and reported in various types of cancers, including leukemia, lymphoma, gastrointestinal, genitourinary, breast and ovarian cancer, head and neck squamous cell carcinoma, lung cancer, melanoma and sarcoma (23). However, little research has been conducted to assess the anticancer potential of CUR in MDS cells and LSCs. In the present study, CUR exhibited growth inhibition and apoptosis induction time- and dose-dependently in both MDS-SKM-1 cells and leukemia stem-like KG1a cells. Thus, we considered CUR may be a potential sensitization agent to ATO in SKM-1 and KGla cells.

ATO has received extensive attention due to its anticancer activities in various cancers by affecting cellular functions via different molecular targets. For instance, ATO can induce apoptosis by activating the caspase cascade, decreasing the mitochondrial membrane potential, and increasing the production of reactive oxygen species $(33,34)$. The most successful application of ATO for the treatment of cancer is currently its use to treat patients with APL by targeting the PML-RARa fusion protein (35), achieving complete remission with only few adverse effects (6). Similarly, ATO has been applied to treat MDS patients but without promising results (11) due to a low response and subsequent relapse. In the present study, ATO could indeed inhibit cell growth and induce partial apoptosis in SKM-1 and KG1a cells in vitro, but high-dose concentrations were needed. In addition, KG1a cells exhibited reduced sensitivity to ATO compared with SKM-1 cells (Fig. 2B), in accordance with the characteristics of LSCs, which may provide an explanation for MDS relapse after treatment with ATO alone.

To solve the problems associated with a low response and easy relapse after treatment with ATO alone, the sensitivity of MDS cells and LSCs to ATO must be enhanced. Thus, we adopted the strategy of combining CUR with ATO to treat SKM-1 and KG1a cells in vitro and explored their synergistic effect. We found that CUR could significantly increase ATO-induced apoptosis and had a synergistic cytotoxic effect with ATO on both SKM-1 and KG1a cells. Previous studies have reported that ATO combined with other agents, including ascorbic acid (11), thalidomide, retinoid acid (10), and low-dose cytarabine (15), can enhance the treatment efficacy in vivo and in vitro. Sánchez et al demonstrated that the addition of CUR increased the efficacy of ATO as an antitumor drug in U937, HL60 and K562 cells (36). However, we reported the first demonstration of the combination of CUR and ATO to treat MDS and leukemia stem-like cells in vitro. These results provide a strong basis for the treatment of MDS by combining CUR with ATO in vivo.

We also explored the mechanisms and searched for the target by which CUR enhanced ATO-induced apoptosis by detecting 43 apoptosis-related proteins using protein array assays in SKM-1 and KG1a cells following treatment with CUR and ATO alone or in combination for $48 \mathrm{~h}$. Thirty-one proteins were modulated (upregulation or downregulation) in SKM-1 cells, whereas 12 proteins were modulated (upregulation or downregulation) in KG1a cells in the combination groups (Table I). These data indicated that co-treatment of these cells with CUR and ATO could affect various targets and pathways of apoptosis, particularly in SKM-1 cells.

Apoptotic signal transduction can proceed via two main signaling pathways, including the death receptor (extrinsic) and the mitochondrial (intrinsic) pathways (37). Caspase-8, which directly cleaves caspase-3, is considered to be the initiator and hallmark of the extrinsic pathway (38). In the present study, caspase-8 was significantly upregulated in SKM-1 cells in response to co-treatment with CUR and ATO, but no change was detected in KG1a cells. These results indicated that co-treatment with CUR and ATO induced SKM-1 cell apoptosis by both extrinsic and intrinsic pathways, leading to a higher sensitivity of SKM-1 cells to ATO compared with KG1a cells. The upregulation of death receptors (TRAILR-2/3/4, Fas) in SKM-1 cells further supported these findings.

Survivin is a member of the inhibitor of apoptosis proteins (IAPs) that is expressed in the vast majority of neoplasms but not in differentiated normal tissue (39). In the present study, survivin protein overexpression was downregulated in both SKM-1 and KG1a cells in the CUR groups and drug combination groups. Some previous reports have shown that the suppression of survivin can lead to apoptosis of cancer cells and can enhance the chemotherapeutic sensitivity of drugs, including cisplatin and doxorubicin, in lung cancer and breast cancer cells $(40,41)$. Notably, we confirmed that suppressing the expression of survivin by siRNA indeed enhanced the sensitivity of SKM-1 and KG1a cells to ATO. These results strongly indicated that survivin may be a potential target of CUR and ATO co-treatment in SKM-1 and KG1a cells. X-linked IAP (XIAP), another member of the IAPs, inhibits the caspase-dependent apoptotic pathway by forming a survivin-XIAP complex (42). The XIAP stability may be disrupted via the suppression of survivin. In the present study, XIAP was significantly downregulated in both cell lines by co-treatment with CUR and ATO, representing another potential mechanism underlying the enhancement of apoptosis in the drug combination groups in these two cell lines.

In summary, we demonstrated that CUR could enhance the sensitivity of MDS-SKM-1 cells and leukemia stem-like KGla cells to ATO by downregulating a potential target survivin protein. Thus, the barriers associated with a poor response and frequent MDS relapse following treatment with ATO alone may be solved by combining CUR with ATO.

\section{Acknowledgements}

The present study was supported by the Science and Technology Project Foundation of Jiangmen City (grant no. 2013019).

\section{References}

1. Nimer SD: Myelodysplastic syndromes. Blood 111: 4841-4851, 2008.

2. Cogle CR, Craig BM, Rollison DE and List AF: Incidence of the myelodysplastic syndromes using a novel claims-based algorithm: High number of uncaptured cases by cancer registries. Blood 117: 7121-7125, 2011. 
3. Sekeres MA, Schoonen WM, Kantarjian H, List A, Fryzek J, Paquette R and Maciejewski JP: Characteristics of US patients with myelodysplastic syndromes: Results of six cross-sectional physician surveys. J Natl Cancer Inst 100: 1542-1551, 2008.

4. Ma X, Does M, Raza A and Mayne ST: Myelodysplastic syndromes: Incidence and survival in the United States. Cancer 109: 1536-1542, 2007.

5. Zeidan AM, Linhares Y and Gore SD: Current therapy of myelodysplastic syndromes. Blood Rev 27: 243-259, 2013.

6. Lengfelder E, Hofmann WK and Nowak D: Impact of arsenic trioxide in the treatment of acute promyelocytic leukemia. Leukemia 26: 433-442, 2012.

7. Mayorga J,Richardson-Hardin C and Dicke KA: Arsenic trioxide as effective therapy for relapsed acute promyelocytic leukemia Clin J Oncol Nurs 6: 341-346, 2002

8. Vey N, Bosly A, Guerci A, Feremans W, Dombret H, Dreyfus F, Bowen D, Burnett A, Dennis M, Ribrag V, et al: Arsenic trioxide in patients with myelodysplastic syndromes: A phase II multicenter study. J Clin Oncol 24: 2465-2471, 2006.

9. Schiller GJ, Slack J, Hainsworth JD, Mason J, Saleh M, Rizzieri D, Douer D and List AF: Phase II multicenter study of arsenic trioxide in patients with myelodysplastic syndromes. J Clin Oncol 24: 2456-2464, 2006.

10. Wei W, Zhou F, Zhang Y, Guo L, Shi H and Hou J: A combination of thalidomide and arsenic trioxide is effective and well tolerated in patients with myelodysplastic syndromes. Leuk Res 36: 715-719, 2012.

11. Galimberti S, Guerrini F, Salvi F, Petrini I, Gioia D, Messa E, Palumbo GA, Cilloni D, Petrini M and Levis A: Arsenic trioxide and ascorbic acid interfere with the BCL2 family genes in patients with myelodysplastic syndromes: An ex-vivo study. J Hematol Oncol 5: 53, 2012.

12. Luo Q, Li Y, Deng J and Zhang Z: PARP-1 inhibitor sensitizes arsenic trioxide in hepatocellular carcinoma cells via abrogation of $\mathrm{G} 2 / \mathrm{M}$ checkpoint and suppression of DNA damage repair. Chem Biol Interact 226: 12-22, 2015.

13. Tao JL, Li LJ, Fu R, Wang HQ, Jiang HJ, Yue LZ, Zhang W, Liu H, Ruan EB, Qu W, et al: Elevated TIM3+ hematopoietic stem cells in untreated myelodysplastic syndrome displayed aberrant differentiation, overproliferation and decreased apoptosis. Leuk Res 38: 714-721, 2014.

14. Pandolfi A, Barreyro L and Steidl U: Concise review: Preleukemic stem cells: Molecular biology and clinical implications of the precursors to leukemia stem cells. Stem Cells Transl Med 2: $143-150,2013$

15. Roboz GJ, Ritchie EK, Curcio T, Samuel M, Provenzano J, Segovia J, Christos PJ, Mathew S, Allen-Bard S and Feldman EJ Arsenic trioxide and low-dose cytarabine for patients with intermediate-2 and high-risk myelodysplastic syndrome. Leuk Res 35: 522-525, 2011

16. Zheng WL, Zhang GS, Xu YX, Shen JK, Dai CW and Pei MF Arsenic trioxide, thalidomide and retinoid acid combination therapy in higher risk myelodysplastic syndrome patients. Leuk Res 32: 251-254, 2008.

17. Goel A and Aggarwal BB: Curcumin, the golden spice from Indian saffron, is a chemosensitizer and radiosensitizer for tumors and chemoprotector and radioprotector for normal organs. Nutr Cancer 62: 919-930, 2010.

18. Du B, Jiang L, Xia Q and Zhong L: Synergistic inhibitory effects of curcumin and 5-fluorouracil on the growth of the human colon cancer cell line HT-29. Chemotherapy 52: 23-28, 2006.

19. Everett PC, Meyers JA, Makkinje A, Rabbi M and Lerner A: Preclinical assessment of curcumin as a potential therapy for B-CLL. Am J Hematol 82: 23-30, 2007.

20. Kamat AM, Sethi G and Aggarwal BB: Curcumin potentiates the apoptotic effects of chemotherapeutic agents and cytokines through down-regulation of nuclear factor-kappaB and nuclear factor-kappaB-regulated gene products in IFN-alpha-sensitive and IFN-alpha-resistant human bladder cancer cells. Mol Cancer Ther 6: 1022-1030, 2007.

21. Bharti AC, Donato N, Singh S and Aggarwal BB: Curcumin (diferuloylmethane) down-regulates the constitutive activation of nuclear factor-kappa B and IkappaBalpha kinase in human multiple myeloma cells, leading to suppression of proliferation and induction of apoptosis. Blood 101: 1053-1062, 2003.

22. Li L, Ahmed B, Mehta K and Kurzrock R: Liposomal curcumin with and without oxaliplatin: Effects on cell growth, apoptosis, and angiogenesis in colorectal cancer. Mol Cancer Ther 6: 1276-1282, 2007.
23. Anand $P$, Sundaram $C$, Jhurani S, Kunnumakkara $A B$ and Aggarwal BB: Curcumin and cancer: An 'old-age' disease with an 'age-old' solution. Cancer Lett 267: 133-164, 2008.

24. Matozaki S, Nakagawa T, Kawaguchi R, Aozaki R, Tsutsumi M, Murayama T, Koizumi T, Nishimura R, Isobe T and Chihara K: Establishment of a myeloid leukaemic cell line (SKNO-1) from a patient with $\mathrm{t}(8 ; 21)$ who acquired monosomy 17 during disease progression. Br J Haematol 89: 805-811, 1995.

25. Nakagawa T, Matozaki S, Murayama T, Nishimura R, Tsutsumi M, Kawaguchi R, Yokoyama Y, Hikiji K, Isobe T and Chihara K: Establishment of a leukaemic cell line from a patient with acquisition of chromosomal abnormalities during disease progression in myelodysplastic syndrome. Br J Haematol 85: 469-476, 1993

26. Zou J, Hong Y, Tong Y, Wei J, Qin Y, Shao S, Wang C and Zhou K: Sonic hedgehog produced by bone marrow-derived mesenchymal stromal cells supports cell survival in myelodysplastic syndrome. Stem Cells Int 2015: 957502, 2015.

27. Fuchs D, Daniel V, Sadeghi M, Opelz G and Naujokat C: Salinomycin overcomes ABC transporter-mediated multidrug and apoptosis resistance in human leukemia stem cell-like KG-1a cells. Biochem Biophys Res Commun 394: 1098-1104, 2010.

28. She M, Niu X, Chen X, Li J, Zhou M, He Y, Le Y and Guo K: Resistance of leukemic stem-like cells in AML cell line KGla to natural killer cell-mediated cytotoxicity. Cancer Lett 318: 173-179, 2012.

29. Uchida H, Tanaka T, Sasaki K, Kato K, Dehari H, Ito Y, Kobune M, Miyagishi M, Taira K, Tahara $\mathrm{H}$, et al: Adenovirus-mediated transfer of siRNA against survivin induced apoptosis and attenuated tumor cell growth in vitro and in vivo. Mol Ther 10: 162-171, 2004.

30. Tefferi A and Vardiman JW: Myelodysplastic syndromes. N Engl J Med 361: 1872-1885, 2009.

31. Yue LZ, Fu R, Wang HQ, Li LJ, Hu HR, Fu L and Shao ZH: Expression of CD123 and CD114 on the bone marrow cells of patients with myelodysplastic syndrome. Chin Med J 123: 2034-2037, 2010

32. Becker MW and Jordan CT: Leukemia stem cells in 2010: Current understanding and future directions. Blood Rev 25: 75-81, 2011.

33. Rojewski MT, Körper S and Schrezenmeier H: Arsenic trioxide therapy in acute promyelocytic leukemia and beyond: From bench to bedside. Leuk Lymphoma 45: 2387-2401, 2004.

34. Qian W, Liu J, Jin J, Ni W and Xu W: Arsenic trioxide induces not only apoptosis but also autophagic cell death in leukemia cell lines via up-regulation of Beclin-1. Leuk Res 31: 329-339, 2007.

35. Emadi A and Gore SD: Arsenic trioxide - An old drug rediscovered. Blood Rev 24: 191-199, 2010

36. Sánchez Y, Simón GP, Calviño E, de Blas E and Aller P. Curcumin stimulates reactive oxygen species production and potentiates apoptosis induction by the antitumor drugs arsenic trioxide and lonidamine in human myeloid leukemia cell lines. J Pharmacol Exp Ther 335: 114-123, 2010.

37. Fulda $\mathrm{S}$ and Debatin KM: Extrinsic versus intrinsic apoptosis pathways in anticancer chemotherapy. Oncogene 25: 4798-4811, 2006.

38. Fulda S: Targeting extrinsic apoptosis in cancer: Challenges and opportunities. Semin Cell Dev Biol 39: 20-25, 2015.

39. Waligórska-Stachura J, Jankowska A, Waśko R, Liebert W, Biczysko M, Czarnywojtek A, Baszko-Błaszyk D, Shimek V and Ruchała M: Survivin - prognostic tumor biomarker in human neoplasms - review. Ginekol Pol 83: 537-540, 2012.

40. Yu DD, Wang CT, Shi HS, Li ZY, Pan L, Yuan QZ, Leng F, Wen Y, Chen X and Wei YQ: Enhancement of cisplatin sensitivity in Lewis lung carcinoma by liposome-mediated delivery of a survivin mutant. J Exp Clin Cancer Res 29: 46, 2010.

41. Xu Y, Zheng W, Wang T, Wang P, Zhu L and Ma X: Genetic protein $\mathrm{TmSm}(\mathrm{T} 34 \mathrm{~A})$ enhances sensitivity of chemotherapy to breast cancer cell lines as a synergistic drug to doxorubicin. Biomed Pharmacother 66: 368-372, 2012.

42. Athanasoula KC, Gogas H, Polonifi K, Vaiopoulos AG, Polyzos A and Mantzourani M: Survivin beyond physiology: Orchestration of multistep carcinogenesis and therapeutic potentials. Cancer Lett 347: 175-182, 2014 